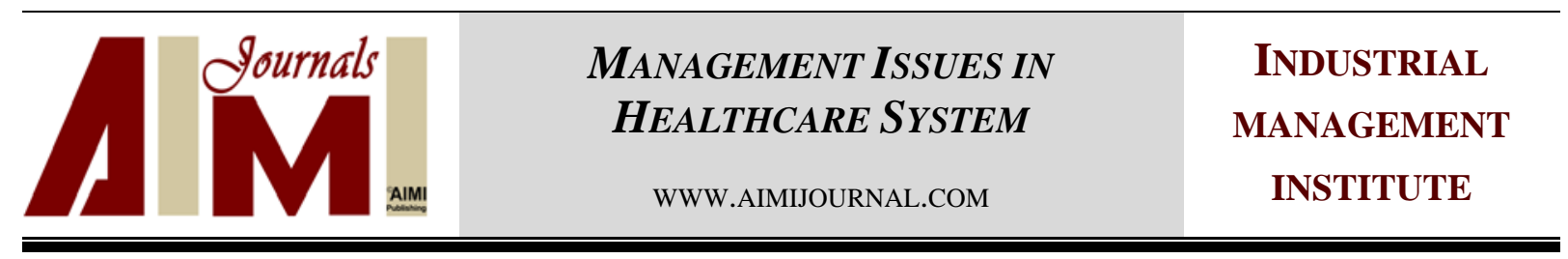

\title{
Knowledge sharing: The key factors in the success of knowledge management system in the organizational health of the employees working in the public universities of Tehran
}

\author{
Asiyeh Sa'adati Azar ${ }^{1 *}$, Mohammad Javad Nasiri ${ }^{2}$, Shahram Nasiri ${ }^{3}$ \\ ${ }^{1}$ Asiyeh Sa’adati Azar, MSc. of information Technology Management, Kharazmi University, Tehran, Iran \\ ${ }^{2}$ Mohammad Javad Nasiri, Instructor, Faculty of Computer, Fasa University, Fasa, Iran \\ ${ }^{3}$ Shahram Nasiri, Instructor, Faculty of Computer, Sirjan University Technology, Sirjan, Iran
}

Keywords:

Knowledge Sharing,

Knowledge

Representation,

Knowledge Acquisition,

Organizational Health of University

Correspondence: a.saadatiazar@yahoo.com

\section{Abstract}

The purpose of this study is to predict the knowledge sharing behavior in the organizational health of public universities in Tehran. The population included employees of Shahid Beheshti, Tarbiat Modarres, Amir Kabir, and Kharazmi universities located in Tehran. For this purpose, a sample size of 320 of employees based on Morgan's table was selected through proportional stratified random sampling and responded to the organizational health and knowledge sharing questionnaire. Research method is quantitative and descriptive and correlational in terms of data collection and objective. In order to analyze the obtained data, statistical methods of regression, correlation coefficient, multivariate data analysis, and measurement tools of SPSS, PLS were used. The results showed that, the observed $r$ at the level of $p$ $<0.05$ indicated a significant positive correlation between knowledge sharing and organizational health of the public universities' employees in Tehran. This study supports the idea that knowledge sharing and its dimensions as a strong predictor largely influences organizational health. 
Knowledge management involves four process of producing, storing, transferring, and applying of knowledge. Many scholars believe that sharing knowledge is the most important factor in the success of knowledge management and is defined as a voluntary publication of experience and skills obtained in the organization (Law \& Ngai, 2008). Sharing knowledge is important to the extent that many have accepted the idea that the success of knowledge management depends on knowledge sharing. In other words, knowledge sharing is the most important part of knowledge management which is in fact the means by which knowledge is shared and the factors which facilitate sharing and transferring the knowledge are knowledge management (Renzl, 2012). Knowledge sharing is the voluntary participation of the acquired skills and experience to other individuals. In other words, knowledge sharing is defined as the action of publishing information among others.

Many researchers believe that it is necessary to have a change in the field of knowledge management from focusing on technology-oriented approaches to human-centered approaches. Hong, Suh, and Koo (2011) defined Knowledge management as a way to simplify and improve the process of sharing, distribution, creation and understanding of organizational knowledge. Davenport and Prusak (1998) defined Knowledge management as the collection, dissemination, and efficient use of knowledge resources. Knowledge sharing is a critical process in modern organization, because successful knowledge sharing leads to sharing intellectuals' capital and increase of the organization's important resources. Only when individuals and group knowledge turns into organizational knowledge, the organizations are enabled to effectively manage these valuable resources (Van den Hooff \& De Ridder, 2004). Knowledge sharing is a bridge between the knowledge of individuals and the organization which could increase innovative capacity and thus, result in a competitive advantage (Cao \& Xiang, 2012). Among the tools measuring knowledge sharing, Van den Hooff and Ridder's (2004) questionnaire of knowledge sharing has gained special attention because it is able to measure two dimensions of knowledge sharing in terms of knowledge representation and acquisition of knowledge (Lin, Wub and Lu, 2012). The objectives of these studies refer to adjusted means for replacing the companies with universities to use tools that are directly related to collaborative studies. Knowledge before being used in organizational levels should be shared and distributed across the organization (Lin, 2007).

Although some believe that knowledge is power, knowledge itself seems to lack power; but what gives power to the people is part of their knowledge shared with others. If we analogize the knowledge of people's mind to the gold in a box, the value of knowledge would reveal when it is shared, like the time, the holder of the gold opens the box and reveals its value. Knowledge sharing is defined as giving and receiving knowledge from others. According to McDermott (1999), when someone is sharing their knowledge, it means that person guides another one with his/her knowledge, insight, and thoughts in order to strengthen the position of that individual. In addition, it is ideal that the person who is sharing his knowledge, be informed of the object and the application of the sharing knowledge as well as the needs and information gaps of the recipient of knowledge. The present study aimed to predict the knowledge sharing behavior in the organizational health of public universities in Tehran. 


\section{Organizational Health}

The term organizational health was first used by Miles in the year 1967 (Korkmaz, 2006; Tsui \& Cheng, 1999) and by proposing a plan for the assessment of the health of the organizations noted that the organization will not always be healthy. Organizational health approach has considerable scientific benefits in term of comprehending the dynamics of organizations and studies and attempts to improve them. Organizational health is the ability of organizations to survive and adapt to the environment and improvement of such ability. As all individuals need health in order to live and fulfill human duties, an organization also as an organic thing requires health organizations to achieve its defined objectives. If that does not provide this health or at least, part of it, conditions and the way to achieve the specified goals would be undermined.

Health status of individuals and organization allows higher performance than usual. In this position, the organization turns to its best, productive, and flexible existence in their class. Lack of continuous motivation in a healthy system makes the system gradually lose its normal position; continuity of lack leads the organization to unfavorable situation. Healthy organizations are a place in where people like to work and are proud of their work. In fact, the organizational health in terms of physical, psychological, safety, belonging, meritocracy, beneficiaries personality and improving their abilities and performing the duties assigned by their own meta systems has significant effect on effectiveness of system's treatment (Saedi, Khalatbari, \& Mouri Najaf Abadi, 2010).

Most of the objectives of the international community in the third millennium, directly or indirectly are related to health. From the viewpoint of scholars and thinkers, nowadays, the biggest challenge with which the leaders of organizations are facing is the development of new management approaches in all parts of the organization. In such an environment, the country's health sector organizations need to develop a management capacity more than other organizations to enhance the capabilities, continuous improvement, and overcoming difficulties (Lynden \& Klingle, 2000). Organizational health is a new concept that includes not only the ability to perform tasks effectively, but also includes the ability for the improvement and growth (Nazem, Karim zadeh, \& Ghaderi, 2010).

A healthy organization is a place where people want to stay and work. Organizational health involves conditions beyond the short-term efficacy of organization and refers to a set of comparatively durable organizational traits. Such a healthy organization not only resists in its own environment but also is able to sufficiently adapt to its environment in a long time and continually create and expand its necessary abilities for its survival (Alvani, 2000).

\section{An Overview of the Consequences of Knowledge Sharing on Organizational Health}

Knowledge sharing is a critical issue for organizations. Organizations would be able to increase their knowledge capabilities and to achieve competitive advantages in comparison with other organizations by proper application of knowledge management and the use of its facilities in the accelerating and facilitating access to information. Because it enables them to develop opportunities, competencies, values, and sustain competitive advantages and therefore, can achieve organizational health (Wang \& Noe, 2010). Indeed, knowledge-based 
management is regarded as a path to empowerment of the staff and increases the efficiency, effectiveness, and organizational health (Balthazovrd, 2004).

In terms of behavior, a person who receives knowledge of the other person, believes that the donor of knowledge is good man, thoughtful, innovative, helpful, and devoted. Therefore, some people are willing to gain others' attentions; thus, they start to share their knowledge and on the other hand, these behaviors contribute to the health and climate of organization. Some people tend to use various methods such as knowledge sharing among others to express their abilities and to motivate themselves. Identifying these people and having them in the areas which require knowledge sharing can help people's motivation, the benefit of others, and the overall success of the organization (Sarlak and Eslami, 2011).

In parallel with the completion and finalization of organizational health questionnaire, Hoy and Mescle (2008) classified organizational health at three levels including institutional, administrative, and technical and seven dimensions, namely the institutional integrity of the institutional level, the influence of the director, consideration (consideration) to build and support the resources related to the administrative level, moral dimension, and scientific emphasis related to the technical level. These dimensions are touched upon briefly below.

\section{Institutional Level and its Dimensions}

Institutional Integrity: This refers to the ability of the organization to adapt to their environment, in a way that maintains the oneness, unity, and integrity of the organization's plans. Institutional integrity programs mean an understanding of the interests of the employees and the organization's ability to adapt to its environment (institutional requirements).

\section{Administrative Levels and its Dimensions}

The Manager's Influence: It is management's ability to influence the heads of his superiors, urging them to pay more attention to the organization's issues and its goals and mission, not facing with administrative hierarchy to provide more services and not being dependent to the head (instrumental need).

Consideration (Observing): This represents the friendly, supportive, and open behavior of manager (expression need).

Structure: Structure clearly defines the director's behavior in identifying working relationships with employees, managers, job expectations, performance standards, and methods of fulfilling a task. Manager's behavior is task-based and working environment is structured and success-oriented. Structuring like consideration is an important aspect of effective leadership (expressive need).

Resources Support: This refers to the organizations which have enough resources for effective performance (instrumental need).

\section{Technical Level and its Dimensions}

Morale: Morale refers to the collective sense of friendliness, openness, and mutual trust between the employees. They create an integrated and coherent place where they do their job 
activity enthusiastically; they love each other and love their job, help each other, and are proud of their job and organization (expressive need).

Scientific Emphasis: This refers to the extent to which the organizations desire for cultural and academic excellence and tries to achieve it. Every organization has high but achievable standards in various areas. In addition, institutional environment for teaching and learning new information in order to achieve organizational standards is strong and regular. Directors and managers of the different levels of organization and their employees try to achieve new success. Employees respect scientific and technical progress along with innovation and creativity as a single purpose and major work. Gaining such results would be possible through the organization.

\section{Method}

This research is applied research and the collection of data is based on the correlation type. The research population is consisted of employees in Tehran public universities. The sample size is obtained by Cochran's sample size formula and organizational health questionnaire was used. The questionnaire is provided by Ahanchian and Monidri (2004) to measure the organizational health at universities. The mentioned questionnaire contained 38 items and in seven subscales (institutional integrity, 7 items; structuring, 5 items; consideration, 4 items; the manager's influence, 5 items; resource support, 4 items; morale, 5 items; and scientific emphasis, 8 items) and it also consisted of Van den Hooff's 10-item questionnaire, which included two dimensions of the acquisition of knowledge (5 questions) and the knowledge representation (5 questions).

In order to measure the knowledge sharing and organizational health as the primary means of data collection they have been considered. Ideas measurement scales were done based on five-point Likert scale which began with "completely disagree" and ended with "totally agree". The questions are scored from 1 to 5 . For the confirmation of the validity of instruments, content validity, convergent validity, and divergent validity were used. Content validity is made by ensuring the consistency between the measured parameters and the existing literature. Such validity was obtained by surveying the experts. Convergent validity refers to the fact that the indices of each structure had a moderate correlation with each other.

Moreover, to determine the reliability of the questionnaires, Cronbach's alpha and AVE coefficient according to the viewpoint of Fornell and Larcker (1981) were used. Cronbach's alpha coefficient is higher than the minimum value of .7 for all the variables in this study. Reliability of AVE coefficient unlike Cronbach's alpha assumes that each index has the same weight and relies upon the actual load factor of each structure and offers a better index of reliability. The reliability of the AVE should achieve a value more than 7 to represent the internal stability of the structure (Fornell \& Larcker, 1981).

Table 1 shows the demographic characteristics of the studied sample. 
Table 1

Demographic Characteristics of the Studied Sample

\begin{tabular}{lll|lll}
\hline Characteristic & Group & Percent & & & \\
\hline Age & Below 30 & $4 \%$ & Length of & Less than One Year & $22 \%$ \\
& $30-35$ & $33 \%$ & Service & $1-2$ & $42 \%$ \\
& $35-40$ & $37 \%$ & & $2-3$ & $13 \%$ \\
& $40-45$ & $21 \%$ & & $3-4$ & $11 \%$ \\
\cline { 2 - 6 } & Above 45 & $5 \%$ & & More than 4 Years & $12 \%$ \\
\multirow{5}{*}{ Degree } & Under Diploma & $9 \%$ & Gender & Women & $45 \%$ \\
& Diploma & $25 \%$ & & Men & \\
& AS & $15 \%$ & & & \\
\end{tabular}

Table 2 presents the convergent validity and reliability of the measuring instruments.

Table 2

Convergent Validity and Reliability of the Measuring Instruments

\begin{tabular}{lcccc}
\hline Research Variables & AVE & Factor Loads & PC>.7 & Cronbach's Alpha Correlation Coefficient \\
\hline Knowledge Sharing & .62 & - & .90 & .89 \\
Knowledge Acquisition & - & .77 & - & - \\
Knowledge Representation & - & .84 & - & - \\
Organizational Health & .69 & - & .79 & .71 \\
Institutional Integrity & - & .91 & - & - \\
Manager's Influence & - & .72 & - & - \\
Resources' Support & - & .76 & - & - \\
Scientific Emphasis & - & .81 & - & - \\
Morale & - & .75 &. & - \\
Structure & - & .66 & - & - \\
Consideration & - & .66 & - & - \\
\hline
\end{tabular}

\section{Results}

After collecting the data, the obtained data were analyzed using statistical software program in the Social Sciences (SPSS) and PLS software.

Table 3 exhibits the coefficients related to the knowledge presentation with the components of organizational health.

Table 3

Coefficients Related to the Knowledge Presentation with the Components of Organizational Health

\begin{tabular}{lccccc}
\hline Component & SD & Regression Coefficient & T-Value & Correlation Coefficient & Level of Sig. \\
\hline Institutional Integrity & .23 & .95 & 24.3 & .44 & .001 \\
Manager's Influence & .26 & .28 & 1.2 & .06 & .25 \\
Resources' Support & .14 & .85 & 2.8 & .44 & .001 \\
Scientific Emphasis & .44 & .16 & .085 & .06 & .438 \\
Morale & .11 & .69 & 14.1 & .01
\end{tabular}


According to the results, source of knowledge representation exerts effect on the components of institutional integrity, resources support, morale, structure, and consideration and can remain in the regression equation while it is unaffected on the principal components of manager's influence and scientific emphasis. The coefficient of determination indicates that the .44 of scores of institutional integrity, resources support, morale, structure, and consideration components are influenced by the component of the knowledge representation from knowledge sharing.

Table 4 represents the coefficients related to the knowledge acquisition with the components of organizational health.

Table 4

Coefficients Related to the Knowledge Acquisition with the Components of Organizational Health

\begin{tabular}{lccccc}
\hline Component & SD & Regression Coefficient & T-Value & Correlation Coefficient & Level of Sig. \\
\hline Institutional Integrity & .14 & .52 & 3.9 & .35 & .002 \\
Manager's Influence & .33 & .32 & 5.1 & .35 & .000 \\
Resources' Support & .27 & .42 & 6.8 & .35 & .018 \\
Scientific Emphasis & .46 & .62 & 4.2 & .35 & .025 \\
Morale & .31 & .82 & 3.03 & .35 & .000 \\
Structure & .17 & .90 & 4.1 & .35 & .000 \\
Consideration & .53 & .55 & 7.18 & .35 & .000 \\
\hline
\end{tabular}

According to the results, source of knowledge acquisition has an influence on the components of institutional integrity, resources support, morale, structure, and consideration and can remain in the regression equation. The coefficient of determination indicates that the .35 of scores of institutional integrity, resources support, morale, structure, and consideration components are under the influence of source of component of the knowledge acquisition from knowledge sharing.

\section{Discussion and Conclusion}

The obtained results on the assessment of the relative contributions of knowledge representation components from knowledge sharing with components of organizational health indicates that there is a significant positive correlation between the components of knowledge representation and institutional integrity, resources support, morale, structure, and consideration components. In other words, when employees exchange experiences, knowledge, and information with each other, it would be expected that the discovery of fact can create a powerful and dynamic organization and increase organizational health. Therefore, in the organization which is under the study, employees believe that the effort to provide greater knowledge, providing causes and its context in a way of sharing experiences, knowledge and information in an organization could create a situation in which leadership's behavior would be more open and friendly. Moreover, respect, mutual trust, cooperation, and support increases. The behavior of the managers in identifying business relations with employees, job expectations, performance standards, and the work methods would be clearer 
and finally enables the organization to the adapt to the environment by maintaining its unity and integrity programs.

Results of the research by Soltan Hosseini and Mousavi (2011) have confirmed these findings. Moreover, the results of the studies by Jong and Hartog (2007), Luke and Verreynne (2006), Darling, Gabrielsson, and Seristo (2007), and Wood (2004) are in line with our results. In such system, behaviors, such as the exchange of ideas between the staff, providing technical definitions, and expertise to help in creating a better understanding, usage of information networks in order to have a better understanding of legal obligations and expression of ideas with clear examples are important. The value and importance of working can be expected to rise among the university staff and they could work in complete comfort and could have active participation. In such circumstances, organizational health will increase at universities.

According to the results, it can be concluded that knowledge presentation can exert positive effects on the organization and its health. With proper knowledge sharing, organizations can improve efficiency, reduce training costs and lower the risk of uncertainty in the organization. The results of regression analysis also showed that the knowledge acquisition component from knowledge-sharing can influence institutional integrity, management authority, morale, structure, and consideration.

Behaviors such as having a discussion between people, recording new events to exploit them in various situations, organizing discussions on beliefs and new ideas for using them in working issues, fulfilling the duties properly and appropriately, and acquiring new information and knowledge will get common and spread. Such behaviors make them to feel more sense of commitment and responsibility toward their job and achieve an integrated business identity. In this system, employees with their entire ability try to achieve goals and success and they always attempt to acquire new knowledge and thus, they feel relaxed and gain mental health. This process will lead to organizational health. Accordingly, the acquisition of knowledge leads to knowledge organization and efficient use of them creates more relaxed atmosphere at university and will increase the health of the organization.

\section{References}

Ahanchian, M. R., \& Monidri, R. A. (2004). The relationship between managers' relationship skills and organizational health. Journal of Humanities \& Social Sciences, 4(12), 41-60.

Alvani, M. (2000). General management (14 ${ }^{\text {th }}$ ed.). Tehran: Nei Publication.

Balthazovrd, P. D. (2004). Role clarity, work overload and organizational support: Multilevel evidence of the importance of support. Journal of Work \& Stress, 68(1), 69-115.

Cao, Y., \& Xiang, Y. (2012). The impact of knowledge governance in knowledge sharing. Management Decision, 50, 591610.

Darling, J., Gabrielsson, M., \& Seristo, H. (2007). Enhancing contemporary entrepreneurship a focus on management leadership. European Business Review, 19(1), 4-22.

Davenport, T. H, \& Prusak, L. (1998). Working knowledge: How organizations manage what they know? Cambridge: Harvard Business School Press.

Fornell, C., \& Larcker, D. F. (1981). Structural equation models with unobservable variables and measurement error: Algebra and Statistics. Journal of Marketing Research, 18(3), 39-50.

Hong, D., Suh, E., \& Koo, C. (2011). Developing strategies for overcoming barriers to knowledge sharing based on conversational knowledge management: A case study of a financial company. Expert Systems with Applications, 38(12), 14417-14427.

Hoy V. K., \& Mescle, C. (2008). Theory, research and practice in educational (S. Abaszadeh, Trans.). Urmia: Urmia University.

Jong, J. \& Hartog, D. (2007). How leaders influence employees innovative behavior? European Journal of Innovation Management, 10 (1), 41-64. 
Korkmaz, M. (2006). The relationship between organizational health and robust vision in elementary schools. Educational Research Quarterly, 1, 14-36.

Law, C. C. H., \& Ngai, E. W. T. (2008). An empirical study of the effects of knowledge sharing and learning behaviors on firm performance. Expert Systems with Applications, 34, 2342-2349.

Lin, H. F. (2007). A stage model of knowledge management: An empirical investigation of process and effectiveness. Journal of Information Science, 33(6), 643-659.

Lin, T. C., Wub, S. \& Lu, C. T. (2012). Exploring the affect factors of knowledge sharing behavior: The relations model theory perspective. Expert Systems with Applications, 39(1), 751-764.

Luke, B., \& Verreynne, M. L. (2006). Exploring strategic entrepreneurship in the public sector. Qualitative Research in Accounting \& Management, 3(1), 4-26.

Lynden J. L., \& Klingle, W. (2000). Supervising organizational health. Supervision Journal, 73(8), 3-5.

McDermott, R. (1999). Why information technology inspired but cannot deliver knowledge management. California Management Review, 41(4), 103-17.

Nazem, F., Karim Zadeh, S., \& Ghaderi, A. (2010). The relationship between knowledge management, organizational health and entrepreneurship of employees in the organization of social welfare. Journal of Social Research, 3(9), 89-115.

Renzl, B. (2008). Trust in management and knowledge sharing: The mediating effects of fear and knowledge documentation. Omega, 36(2), 206-220.

Saedi, S., Khalatbari, J., \& Mouri Najaf Abadi, N. (2010). The relationship between work quality, organizational health and job satisfaction. Journal of News in Organizational \& Industrial Quarterly, 1(4), 55-64.

Sarlak, M. A., \& Eslami, T. (2011). Knowledge sharing in Sharif Technical University: Approach of social capital. Quarterly Journal of Public Administration, 3(8), 1-18.

Soltan Hosseini, M., \& Mousavi, Z. (2011). Determining the contribution of knowledge management in organizational health of physical training office and sport boards of Isfahan City. Sport Management Research \& Movement Science, 2(3), 51-63.

Tsui K. T., \& Cheng, Y. C. (1999). School organizational health and teacher commitment: A contingency study with multilevel Analyses. Educational Research \& Education, 3, 429-268.

Van den Hooff, B., \& De Ridder, J. A. (2004). Knowledge sharing in context: The influence of organizational commitment, communication climate and CMC use on knowledge sharing. Journal of Knowledge Management, 8(6), 117-130.

Wang, S., \& Noe, R. A. (2010). Knowledge sharing: A review and directions for future research. Human Resource Management Review, 20, 115-131.

Wood, M. (2004). The relationship between knowledge sharing management and organizational culture (M. Mehman Navaz). Mashhad: Ferdowsi University Publication. 